\title{
A primary care, multi-disciplinary disease management program for opioid-treated patients with chronic non-cancer pain and a high burden of psychiatric comorbidity
}

\author{
Paul R Chelminski*1, Timothy J Ives ${ }^{1,2}$, Katherine M Felix ${ }^{1}$, \\ Steven D Prakken1, Thomas M Miller ${ }^{1}$, J Stephen Perhac ${ }^{1}$, \\ Robert M Malone ${ }^{1,2}$, Mary E Bryant ${ }^{1,2}$, Darren A DeWalt ${ }^{1,3}$ and \\ Michael P Pignone ${ }^{1,3}$
}

Address: ${ }^{1}$ Department of Medicine, University of North Carolina at Chapel Hill School of Medicine, Chapel Hill, North Carolina, USA, ${ }^{2}$ Division of Pharmacotherapy, University of North Carolina at Chapel Hill School of Pharmacy, Chapel Hill, North Carolina, USA and ${ }^{3}$ Robert Wood Johnson Clinical Scholars Program, University of North Carolina at Chapel Hill School of Medicine, Chapel Hill, North Carolina, USA

Email: Paul R Chelminski* - paul_chelminski@med.unc.edu; Timothy J Ives - tjives@med.unc.edu;

Katherine M Felix - claynef@mindspring.com; Steven D Prakken - sprakken@earthlink.net; Thomas M Miller - thomas_miller@med.unc.edu; J Stephen Perhac - john_perhac@med.unc.edu; Robert M Malone - rmalone@med.unc.edu; Mary E Bryant - bbryant@med.unc.edu; Darren A DeWalt - dewaltd@med.unc.edu; Michael P Pignone - michael_pignone@med.unc.edu

* Corresponding author

\section{Published: 13 January 2005}

BMC Health Services Research 2005, 5:3 doi:10.1186/1472-6963-5-3

This article is available from: http://www.biomedcentral.com/I472-6963/5/3

(C) 2005 Chelminski et al; licensee BioMed Central Ltd.

This is an Open Access article distributed under the terms of the Creative Commons Attribution License (http://creativecommons.org/licenses/by/2.0), which permits unrestricted use, distribution, and reproduction in any medium, provided the original work is properly cited.

\begin{abstract}
Background: Chronic non-cancer pain is a common problem that is often accompanied by psychiatric comorbidity and disability. The effectiveness of a multi-disciplinary pain management program was tested in a 3 month before and after trial.

Methods: Providers in an academic general medicine clinic referred patients with chronic non-cancer pain for participation in a program that combined the skills of internists, clinical pharmacists, and a psychiatrist. Patients were either receiving opioids or being considered for opioid therapy. The intervention consisted of structured clinical assessments, monthly follow-up, pain contracts, medication titration, and psychiatric consultation. Pain, mood, and function were assessed at baseline and 3 months using the Brief Pain Inventory (BPI), the Center for Epidemiological Studies-Depression Scale scale (CESD) and the Pain Disability Index (PDI). Patients were monitored for substance misuse.
\end{abstract}

Results: Eighty-five patients were enrolled. Mean age was 51 years, $60 \%$ were male, $78 \%$ were Caucasian, and $93 \%$ were receiving opioids. Baseline average pain was 6.5 on an II point scale. The average CESD score was 24.0, and the mean PDI score was 47.0. Sixty-three patients (73\%) completed 3 month follow-up. Fifteen withdrew from the program after identification of substance misuse. Among those completing 3 month follow-up, the average pain score improved to $5.5(p=0.003)$. The mean PDI score improved to $39.3(\mathrm{p}<0.00 \mathrm{I})$. Mean CESD score was reduced to $18.0(\mathrm{p}<0.00 \mathrm{I})$, and the proportion of depressed patients fell from $79 \%$ to $54 \%(p=0.003)$. Substance misuse was identified in 27 patients $(32 \%)$.

Conclusions: A primary care disease management program improved pain, depression, and disability scores over three months in a cohort of opioid-treated patients with chronic non-cancer pain. Substance misuse and depression were common, and many patients who had substance misuse identified left the program when they were no longer prescribed opioids. Effective care of patients with chronic pain should include rigorous assessment and treatment of these comorbid disorders and intensive efforts to insure follow up. 


\section{Background}

Chronic, non-cancer pain, defined as pain of greater than 3 months duration, is a common, important health issue. The prevalence of chronic pain ranges from $20 \%$ to $60 \%$ [1]. The prevalance of low back pain is greater than $30 \%[2]$, and the prevalance of migraine is approximately $15 \%[3,4]$. Pain disorders, including headache, back pain, arthritis and other musculoskeletal pain, are estimated to cost the United States economy $\$ 61$ billion per year in lost productive time [5]. It is frequently asserted that chronic non-cancer pain is undertreated [6-8].

The optimal approach to treating chronic pain is controversial [9-13]. The realization that acute pain and cancer pain were often undertreated led to a liberalization of opioid use in these populations in the late 1980's and throughout the 1990's [6,14-16]. Subsequently, many advocates and practitioners called for an increase in the use of opioids for patients with chronic non-cancer pain as well $[14,17,18]$. Other experts assert that use of opioids for chronic pain should be limited $[10,19])$. used with caution [20], or eschewed altogether due to potential for substance misuse and lack of proven efficacy [13].

In large part, uncertainty about how to best manage patients with chronic pain stems from a lack of research in this area [21]. The limited available research comes from studies performed in specialty practice settings $[11,22$ 25]; few studies have examined the care of chronic pain in primary care $[26,27]$. Unlike other common chronic diseases such as congestive heart failure or diabetes, there are few clinical trials to inform practice guidelines.

Chronic pain management is complex. Like other chronic diseases, chronic pain is multi-faceted, and it is attended by its own set of comorbidities. It is complicated by substantial psychological and functional impairment in the forms of depression, disability, and loss of livelihood [2830]. It is also costly. Patients with depression and back pain or migraine incur 3 to 4 times higher medical costs than patients with these pain conditions alone [31].

Generalists, even if well-versed in the biopsychosocial model of disease, often feel unprepared to manage chronic pain. They may lack the training in using certain pharmacological regimens, such as combining chronic opioids with psychiatric and pain modulating agents $[27,32]$. They may fear regulatory scrutiny and sanction when prescribing opioids, and they may be wary of fostering opioid dependence, misuse or addiction [33,34]. These barriers result in variations and inconsistencies in care that leave both patients and providers frustrated.

We developed a disease management program to improve the management of chronic pain in opioid-treated patients attending an academic general medicine practice. Traditional models of office-based care focus on diagnonsis and acute management of medical problems in the context of a single provider-patient relationship. In contrast, disease management emphasizes: (1.) The use of multi-disciplinary teams providing integrated care; (2.) Evidence-based algorithms; (3.) Interval visits to monitor response to therapy; and (4.) Information systems that permit tracking of outcomes and adjustment of therapy [35-39]. We applied these principles in developing and implementing an intensive, structured, and coordinated program to improve the management of patient with chronic pain. We focused our program on patients treated with opioid medications and attempted to provide an environment that would allow the safe and effective use of these drugs. We sought to determine if this program could improve pain, functional, and psychiatric outcomes in a 3 month uncontrolled trial.

\section{Methods}

\section{Development of the program}

In designing the program, we reviewed existing research, contacted experts, and conducted informal assessments of the main barriers to effective pain management in our practice [40]. Barriers existed at the provider and patient levels. These included part-time providers, frequent provider turnaround, physicians in training, and a socio-economically-disadvantaged, geographically dispersed patient population with multiple comorbidities. We applied lessons and systems from existing disease state management programs in diabetes, anticoagulation, and heart failure in our practice [41].

\section{Patient recruitment}

Patients were eligible if they had pain of greater than 3 months duration and were either taking or considering opioid therapy. Attending and resident physicians were encouraged to refer patients if they were having difficulty managing their pain or if they suspected misuse of opioid medications. We publicized the program through educational conferences with residents and attendings and through informal communication within our practice.

\section{Baseline assessment}

After obtaining informed consent, a research assistant administered a comprehensive baseline assessment to gather socio-demographic data and review the medical history with an emphasis on the medical management of pain. Validated measures of pain, disability and psychological status were included. Using an 11 point scale, the Brief Pain Inventory (BPI) asked patients to rate their pain at the time of the interview and at its worst, least, and average over the past month $[42,43]$. The 7 item Pain Disability Index (PDI), a measure of pain related disability, asked patients to rate the degree of disability on a 10 point scale 
[44-47]. Higher scores indicate higher disability and the scale discriminates between high and low levels of disability. To assess depression, we used the Center for Epidemiological Studies-Depression Scale (CESD) [48]. This twenty item tool rates affective symptoms on a scale of 0 to 3 .

\section{Intervention}

Patients were managed by a multi-disciplinary team consisting of the patient's primary care physician, a clinical pharmacist, a program assistant with training in health behavior, and a psychiatrist with sub-specialization in pain management who saw patients with the team one half-day per week. One nurse was dedicated to checkingin study patients and obtaining urine specimens. At entry, all patients signed a Medication Contract (Appendix A) [49] and provided a sample of urine for toxicological testing (UTS) [50,51]. The Medication Contract specified the conditions under which opioids would or would not be prescribed.

The clinical pharmacist or psychiatrist modified or titrated a patient's pain medications in consultation with the primary care physician. During titration of medications, patients returned at one month intervals. Medical management adhered to published guidelines and expert opinion on the management of chronic, non-cancer pain [17,52-54]. The principles of management were:

- Longer-acting opioids (long-acting morphine, fentanyl patches, methadone, sustained-release oxycodone) were initiated in patients who had been receiving short-acting agents that were only partially effective.

- Short-acting, potent opioids (usually oxycodone preparations) were prescribed for breakthrough pain.

- Longer-acting opioids were titrated at interval visits.

- Less costly, generic medications (e.g. methadone and long-acting morphine) were preferred over proprietary products of equal or lesser efficacy [55].

- Tricyclic anti-depressants, gabapentin, and other agents were used adjunctively, especially for neuropathic pain.

To address psychiatric comorbidity, patients with depression and other complex psychiatric conditions (e.g. psychotic depression and bipolar disorder with substance misuse) received psychiatric evaluation. Depression was diagnosed based on clinical interview and CESD score. In addition, primary care physicians could request psychiatric consultation on patients who had unaddressed psychiatric problems. The clinical pharmacist, psychiatrist and primary care physicians used CESD scores to guide treat- ment of patients scoring in the depressed range. The program, however, did not employ a strict protocol for depression treatment.

As defined in our medication agreement with participants, we prospectively monitored substance misuse through clinical history, review of medications, communication with pharmacies and providers, and urine toxicological screening (UTS). Medications were documented in the electronic medical record and our program database. Discrepencies and inconsistencies were discussed with the patient's primary provider. We contacted a patient's pharmacy to verify procurement of medications, and, if substance misuse was suspected, we contacted additional pharmacies to ascertain whether or not a patient was receiving opioids from multiple sources. A UTS was obtained at each visit and was correlated with the patient's reported history of medication use. In collaboration with our institution's toxicologist, results of the UTS were verified using the appropriate confirmatory assays. For example, the presence or absence of "opiates" on the UTS was confirmed using gas chromatography. In addition, all positive results for amphetamines were confirmed with gas chromatography due to the possibility of assay interference from other medications $[50,51]$.

We defined serious substance misuse prospectively as any of the following: 1. Cocaine or amphetamines detected on UTS; 2 . Procurement of opioids from more than one provider on a regular basis ("doctor collecting"); 3. Diversion of opioids; 4 . UTS negative on at least two occasions for prescribed opioids in the context of a reported history that the patient was taking the medication as prescribed (We considered repeatedly "negative" urines as an indicator of possible diversion.); 5. UTS positive on at least two occasions for opioids not prescribed by our practice (an inappropriate or inconsistent urine). A positive cannabinoid finding on UTS was not defined as serious substance misuse for the purposes of our study, but we counseled patients to refrain from marijuana use.

Patients were advised at entry into our program (and in the Medication Contract) that serious violations of the contract would result in discontinuation of opioids. Past instances of serious misuse were not subject to sanction. We constituted a formal practice-wide committee to evaluate and respond to suspected misuse. It consisted of the practice director, two attending physicians, a clinical pharmacist, two resident physicians, and a nurse. The committee deliberated through secure email and considered the violations defined above. Patients committing serious substance misuse were offered referral to substance abuse experts at our institution. In most cases, opioid therapy would be reconsidered in 6 months if the patient participated in substance abuse counseling (The practice 
Table I: Univariate Analysis

\begin{tabular}{|c|c|}
\hline & $\mathbf{N}=\mathbf{8 5}$ \\
\hline Mean age, $y( \pm S D)$ & $51(9.6)$ \\
\hline Range & $27-76$ \\
\hline Male, $\%$ & 60 \\
\hline White Race, \% & 78 \\
\hline \multicolumn{2}{|l|}{ Marital Status, \% } \\
\hline Married & 49 \\
\hline Stable relationship & 7 \\
\hline Unmarried & 44 \\
\hline Disabled, \% & 65 \\
\hline \multicolumn{2}{|l|}{ Education, \% } \\
\hline Not high school graduate & 38 \\
\hline HS graduate & 28 \\
\hline Some college & 34 \\
\hline Income $<\$ 20,000 / y r, \%$ & 83 \\
\hline Medicare or Medicaid, \% & 58 \\
\hline Uninsured,\% & 29 \\
\hline History of Smoking, \% & 87 \\
\hline H/O Alcohol Use, \% & 75 \\
\hline $\mathrm{H} / \mathrm{O}$ Substance Use, \% & 44 \\
\hline H/O Depression, \% & 51 \\
\hline
\end{tabular}

policy addressing substance misuse is included as Appendix B.).

\section{Reassessment}

At 3 month follow-up, a research assistant reassessed each patient's clinical status. Pain, disability, and mood scores were re-measured using the instruments previously described. The research assistant was not blinded to study participation status.

\section{Analysis}

Descriptive statistics are reported as means and percents. Paired t-tests were used to compare changes in pain, disability and depression scores from baseline to 3 month follow-up. McNemar's test was used to measure differences in proportions of patients receiving treatment for depression at 0 and 3 months. We also compared changes in pain scores based on changes in opioid dose. All analyses were performed using Stata 7.0 (College Station, TX).

The research protocol was approved by the University of North Carolina School of Medicine Committee on the Protection of the Rights of Human Subjects. The funding sources had no role in the collection or interpretation of the results.

\section{Results}

Between December 2002 and May 2003, 85 patients agreed to participate in the study. Table 1 presents the baseline demographic characteristics of the study partici- pants. All patients completed baseline assessment and 63 (73\%) completed the 3 month assessment. Of the 22 patients who did not complete 3 month assessment, 15 did not return after a serious violation of the medication contract led to the discontinuation of opioids, 4 patients were lost to follow up, and 3 changed their venue of primary care. There were no important differences in baseline demographic, pain, depression, or disability scores between completers $(n=63)$ and all non-completers ( $n$ $==22$ ), although some differences emerged among noncompleters who committed substance misuse $(\mathrm{n}=15)$ (Table 2.).

\section{Patient characteristics}

The average age of patients was 51 years, $60 \%$ were male, and $78 \%$ were white, most ( $83 \%$ ) had an income less than $\$ 20,000$ per year and 65\% were disabled. Forty-four percent had a history of illicit substance use (e.g. marijuana, cocaine, amphetamines). All patients had pain of at least 3 months duration and $90 \%$ had pain for greater than 1 year. At baseline 93\% were receiving opioids. At 3 month follow up, 97\% were receiving opioids.

Table 3 presents the principal pain types. The lumbar spine was the most frequently involved primary site. Overall, axial spine pain accounted for $49 \%$ of the primary pain reported by patients. Myofascial pain and polyarticular arthritis were also frequently represented. Patients in the "Other" category commonly had mixed etiologies of pain, often attributable to previous trauma or surgery. One chronic headache patient is included in this category.

\section{Effect of the intervention}

Table 4 presents the effect of the intervention on pain, functional status and depression. Baseline results reveal high pain scores. The worst pain was 9.2, the least pain was 4.6 , the average pain was 6.5 , and current pain was 6.8 . The average PDI score, 47.0, suggested substantial disability. There was a high prevalence of depression. The mean CESD score, 24.0, falls in the "severely depressed" category of the scale.

At 3 month follow up, BPI pain scores improved by 12\% to $15 \%$, and all reductions were statistically significant. The mean depression score improved from 24.0 to 18.0 (p $<0.001)$, and the proportion of patients scoring in the depression range decreased from $79 \%$ to $54 \%(p=0.003)$. We did not correct for multiple comparisons because of the exploratory nature of our analyses.

Some authors have demonstrated that the conventional cutoffs for the CESD (depression $\geq 15$; severe depression $\geq 22$ ) may lack specificity in patients with chronic pain and have proposed a CESD threshold of 27 for diagnosing 
Table 2: Characteristics of Study Completers and Non-Completers

\begin{tabular}{|c|c|c|c|c|c|}
\hline Characteristic & $\begin{array}{c}\text { Completers }(\mathrm{N}= \\
63)\end{array}$ & $\begin{array}{c}\text { Non-Completers } \\
(\mathbf{N}=\mathbf{2 2})\end{array}$ & P-Value & $\begin{array}{l}\text { Non-Completers } \\
\text { with Substance } \\
\text { Misuse }(N=15)\end{array}$ & P-Value \\
\hline Age, y & 51 & 49 & 0.422 & 48 & 0.215 \\
\hline$\%$ Male & 62 & 55 & 0.544 & 67 & 0.732 \\
\hline$\%$ White & 81 & 68 & 0.216 & 60 & 0.083 \\
\hline $\begin{array}{l}\text { \% High School } \\
\text { Graduate }\end{array}$ & 62 & 62 & 0.975 & 64 & 0.890 \\
\hline \% Disabled & 66 & 63 & 0.815 & 54 & 0.405 \\
\hline$\%$ Uninsured & 29 & 32 & 0.774 & 33 & 0.716 \\
\hline \% Substance Use & 40 & 55 & 0.226 & 67 & 0.059 \\
\hline CESD & 24 & 27 & 0.416 & 31 & 0.050 \\
\hline PDI & 47 & 41 & 0.141 & 46 & 0.810 \\
\hline \multicolumn{6}{|l|}{ Pain Scores } \\
\hline $\begin{array}{l}\text { Worst in last } \\
\text { month }\end{array}$ & 9.2 & 9.3 & 0.727 & 9.2 & 0.946 \\
\hline Least in last month & 4.6 & 4.4 & 0.768 & 4.7 & 0.884 \\
\hline $\begin{array}{l}\text { Average in last } \\
\text { month }\end{array}$ & 6.5 & 6.5 & 0.925 & 6.6 & 0.861 \\
\hline Current pain & 6.8 & 7.3 & 0.361 & 7.5 & 0.279 \\
\hline
\end{tabular}

Table 3: Primary Pain Type $(\mathbf{N}=\mathbf{8 5})$

\begin{tabular}{lc}
\hline & Number (\%) \\
\hline Spine & $42(49)$ \\
$\quad$ Lumbar & $30(35)$ \\
$\quad$ Cervical & $7(8)$ \\
$\quad$ Thoracic & $5(6)$ \\
Diffuse (Fibromyalgia, Chronic & $13(15)$ \\
fatigue syndrome) & \\
Polyarthritis & $8(9)$ \\
Knee & $5(6)$ \\
Abdomen & $4(5)$ \\
Diffuse neuropathic & $4(5)$ \\
Elbow \& Hip & $2(2)$ \\
Other & $7(8)$ \\
\hline
\end{tabular}

depression in this population [56]. Using this threshold, the proportion of patients scoring in the depressed range decreased from $38 \%$ to $24 \%$ ( $\mathrm{p}=0.049$ ). Pharmacologically, depression was undertreated at baseline. The proportion of depressed patients receiving antidepressants increased from $44 \%$ at baseline to $52 \%$ at 3 months $(\mathrm{p}=0.059)$.

\section{Relationship between pain and opioid dosing}

The mean daily opioid dose in milligram equivalents of morphine increased from $72 \mathrm{mg}$ per day to $91 \mathrm{mg}$ per day (A milligram morphine equivalent approximates a milligram of oxycodone.). Forty-eight percent of patients had their opioid dose increased over 3 months. In these patients, the mean opioid equivalent increased from 53 $\mathrm{mg}$ to $105 \mathrm{mg}$ per day. No clear relationship emerged between opioid dosing and improvements in pain, disability, and depression scores, after adjusting for baseline pain, disability and depression (Table 5.).

\section{Substance misuse}

Twenty-seven patients (32\%) committed some form of serious substance misuse (Table 6.). Although we confirmed only one instance of diversion, we suspect that patients with repeatedly negative UTS's or inconsistent UTS's may have been diverting their medications. Substance misusers accounted for the preponderance of subjects who dropped out of the study. Table 2 compares selected baseline characteristics between substance misusers who did not complete three months and subjects who completed the trial. Although the numbers are small, there is a trend toward greater representation of non-white race, history of illicit substance use, worse depression, and higher pain scores at baseline assessment among substance misusers who did not complete the trial.

\section{Discussion}

We found that a multi-disciplinary, primary care-based, disease management program can improve pain, depression and disability scores in opioid-treated patients with chronic pain in a 3 month uncontrolled trial. The improvements across all outcomes support an improved quality of life resulting from the intervention. These improvements were obtained using an approach that balanced the potential benefits and adverse effects of opioids. 
Table 4: Pre and Post Intervention ( $=63)$

\begin{tabular}{|c|c|c|c|c|}
\hline & Pre & Post & Improvement, \% & P-Value* \\
\hline $\begin{array}{l}\text { Pain at worst in the last } \\
\text { month\& }\end{array}$ & 9.2 & 8.1 & 12 & $<0.001$ \\
\hline $\begin{array}{l}\text { Pain at least during the last } \\
\text { month }\end{array}$ & 4.6 & 3.9 & 15 & 0.038 \\
\hline $\begin{array}{l}\text { Pain on average during the } \\
\text { last month }\end{array}$ & 6.5 & 5.5 & 15 & 0.003 \\
\hline Pain right now & 6.8 & 5.8 & 15 & 0.014 \\
\hline Pain Disability Index & 47.0 & 39.3 & 16 & $<0.001$ \\
\hline CESD & 24.0 & 18.0 & 25 & $<0.001$ \\
\hline \multicolumn{5}{|l|}{$\%$ CESD in depression range: } \\
\hline Conventional cutoffs $t$ & 79.4 & 54.0 & 32 & $0.003 \notin$ \\
\hline Chronic pain cuttoffs $\pi$ & 38.1 & 23.8 & 37 & $0.049 t$ \\
\hline \% Depression medication & 44.4 & 52.4 & 15 & $0.059 \notin$ \\
\hline
\end{tabular}

* Paired t-test except where indicated

EMcNemar's test

\&Score $1-3$ is mild pain; 4-6, moderate pain; $7-10$, severe pain

$\notin$ Score of $\geq 15$

IScore of $\geq 27$

Table 5: Effect of Opioid Increase on Pain $(N=63)$

\begin{tabular}{|c|c|c|c|}
\hline & \multicolumn{2}{|c|}{ Opioids Increased } & \multirow[t]{2}{*}{ P-Value } \\
\hline & Yes $(n=30)$ & No $(n=33)$ & \\
\hline$\Delta$ Pain at worst in the last month & 1.40 & 0.99 & $0.37^{*}$ \\
\hline$\Delta$ Pain at least during the last month & 0.80 & 0.52 & $0.66^{*}$ \\
\hline$\Delta$ Pain on average during the last month & 0.96 & 0.94 & $0.93^{*}$ \\
\hline$\Delta$ Pain right now & 1.14 & 0.87 & $0.70 *$ \\
\hline$\Delta$ Pain Disability Index & 8.34 & 7.03 & $0.63 \pi$ \\
\hline$\triangle$ CESD & 5.21 & 6.71 & $0.74 €$ \\
\hline
\end{tabular}

* Adjusted for baseline pain

IIAdjusted for baseline PDI

E Adjusted for baseline CESD

Table 6: Substance Misuse $(\mathbf{N}=\mathbf{2 7})$

\begin{tabular}{lc}
\hline Misuse & Number (\%) \\
\hline Stimulants on UTS & $13(15)$ \\
Cocaine & $11(14)$ \\
Amphetamines & $2(2)$ \\
Diversion & $1(1)$ \\
Doctor collecting & $3(3)$ \\
Inappropriate/lnconsistent UTS & $2(2)$ \\
Negative ("Clean") Urines & $7(8)$ \\
Prescription adulteration & $1(1)$ \\
\hline
\end{tabular}

We hyothesize that these improvements resulted from the combined effects of systematizing pain management and treating depression. Improvements appear independent of opioid dosing. The clinical significance of the $12 \%$ to $15 \%$ improvement in pain scores is unclear. Uncontrolled trials in specialty pain clinics have reported a $20 \%$ to $25 \%$ reduction in pain scores [57]. Some research suggests that a $30 \%$ decrease in pain scores (i.e. about 2 points) represents clinically significant relief of pain [58], but the issue of how to interpret pain scales clinically is not resolved.

The improvement in depression scores was clinically important and may reflect combined effects of intensification of pharmacological management for depression and pain and the systematization of care. Although the recip- 
rocal relationship between pain and depression has been established in previous studies, the effect that treating one condition has on the other has not been well-assessed [29]. One recent study demonstrated that the presence of severe pain predicted a poor response to antidepressant therapy, and thus it is plausible that intensifying pain management would have a beneficial effect on depression [59]. Clearly, the improvements in depression scores seen in this study cannot be attributed to increasing antidepression pharmacological therapy alone because the proportion of patients treated with anti-depressants increased from $44 \%$ to $52 \%$ only. We have since added a structured treatment algorithm to increase the use of antidepressants. It is important to note that there was a statistically signficant trend toward greater depression among substance misusers who did not complete the trial; thus, it is possible that the trial overestimates the effect of multidisciplinary management on depression outcomes.

To our knowledge, this is the first study to prospectively examine the effects of multi-discplinary pain management on the outcomes of pain, disability, depression, and substance misuse in an academic primary care practice caring for a wide range of patients. Previous studies conducted in a military clinic[60] and a health maintenance organization [26] demonstrated improved pain and functional scores with systematic, multidisciplinary intervention. The military trial was uncontrolled and enrolled referred patients into a specialty clinic. The HMO trial was conducted in a primary care setting. It was controlled, and did evaluate pain, function and mood outcomes. Neither study systematically monitored substance misuse.

We documented a high prevalence of substance misuse $(32 \%)$. We did not assess addiction per se. The prevalence of substance misuse and addiction in patients receiving chronic opioids is unclear and depends on the populaton under study. Some authors have asserted that addiction and substance misuse are uncommon consequences of opioid use for pain. One widely cited reference estimated the prevalence of addiction at approximately 4 in 10,000 treated patients [61]. Others have reported prevalences of addiction ranging from $3 \%$ to $17 \%[62,63]$. A recent retrospective study in a primary care setting documented a high prevalence of opioid misuse: $24 \%$ in a resident physician clinic and 31\% in a Veterans Administration outpatient clinic[64], but the criteria used to determine the prevalence of opioid misuse were limited by chart review. Some behaviors defined as indicators of opioid misuse (e.g. lost or stolen medications, requests for early refills) could be construed as indicators of inadequately treated pain (i.e. "pseudoaddiction"[65]) and not substance misuse or addiction.
Opioid misuse not only complicates the management of pain in the individual patient, but has negative societal consequences as well, especially when opioids are diverted from their intended use [66-68]. Several states have documented increases in unintentional deaths from opioids, especially diverted methadone [69-71]. National surveys demonstrate dramatic increases in the non-medical use of OxyContin ${ }^{\circledast}$ and other prescription drugs among teens and young adults $[72,73]$. The trauma literature has documented recent increases in opioid use among patients admitted to trauma centers [74]. In response, there have been state and national initiatives to reduce prescription drug misuse $[75,76]$. Though high rates of substance misuse are a source of concern, our program may serve as an example for how care can be organized to reduce misuse without eschewing the benefits of opioid medications.

Although the prevalence of substance misuse in our study population is higher than reported in clinical trials of opioids, these trials have occurred in specialty settings with selected populations. They excluded patients with a history of substance misuse, or have not systematically monitored patients for substance misuse [11,12,23,66,77]. In addition, they commonly excluded patients with psychiatric illness (including depression) which is a strong predictor of substance misuse [23,66,78-80]. Patients in our program had a high baseline prevalence of depression, previous substance and alcohol abuse, and other psychiatric disorders (Table 1.). The strong relationship between mental illness and substance abuse disorders is well known and thus the high prevalence of substance misuse is not entirely unexpected [81]. Previous studies of mental illness have documented a high coexisting prevalence of substance and alcohol misuse: $32 \%$ with unipolar depression; $61 \%$ with bipolar depression; $47 \%$ with schizophrenia; $84 \%$ with personality disorders: and $24 \%$ with anxiety disorders $[78,82]$.

We specifically sought out patients whose pain management was difficult for providers or in whom substance misuse was suspected. Many had established or suspected psychiatric diagnoses. How to identify chronic pain patients at risk for drug misuse and to treat their pain remains a challenge [83-89]. The pattern of substance misuse in our population often suggested polysubstance abuse; this places patients at especially high risk of morbidity and mortality [90]. Although patients committing substance misuse were offered substance abuse treatment referral, only two followed through and most did not return to our program. The option of pain management without the use of opioid analgesics was offered to all patients who committed substance misuse. 
The difficulty in obtaining mental health and substance abuse treatment services is a pressing public health issue and a topic of national debate in the United States [81]. In our sample there was a clear trend toward increased comorbid depression among substance misusers who did not complete three month follow up (Table 2.). Despite the availability of on-site psychiatric consultation, our program was not successful in retaining and managing a challenging subset of patients with substance misuse and depression.

We are aware that some of our substance misusing patients migrated to other practices in order to obtain opioids and other controlled substances. Our program implemented policies to prevent migration of patients within our practice (Appendix B.) and the University of North Carolina Health Care System. The cornerstone of these policies was meticulous documentation in an electronic medical record that is accessible to all physicians at our medical center and to hospitals and physicians affiliated with our system in the surrounding communities. In general, though, we have no direct control over migration that occurs outside of our practice and our health care system. In order to curtail migration and "doctor shopping," some states have implemented centralized monitoring systems for opioids and other controlled substances. North Carolina is currently exploring the feasibility of such a system. A description of the operational state monitoring programs is available online through the United States Drug Enforcement Agency Diversion Control Program website [91].

We believe that our results may be generalizable to other academic primary care practices that serve diverse patient populations with a high burden of medical and psychiatric comorbidity. The etiologies and sites of pain were similar to those reported in population-based epidemiological surveys and clinical trials in primary care, except that headache was under-represented in our population $[1,12,92]$. The results replicate epidemiological research that demonstrates a strong interaction between pain and the psychiatric comorbidities of depression and substance misuse $[87,88]$.

Our study may be more applicable to the general medical setting than previous trials examining the effects of opioids on chronic pain because we did not exclude patients with serious psychiatric comorbidity or those suspected of substance abuse. To be effective, pain management should encompass more than pharmacological management directed at pain scores; it should address a variety of behavioral and psychosocial factors that contribute to suffering $[86,93]$.
Our study has several limitations. It was uncontrolled and of relatively short duration. The research assistants were not blinded to pre- and post-treatment assessments. The improvements could reflect secular trends, although the chronic nature of our patients' symptoms and disability makes this less likely, and improvements were noted across all of the pre-specified outcomes. Not all patients receiving chronic opioids in our practice were referred. Thus, we may have over-estimated the prevalence of substance misuse because providers were more likely to refer "problem" patients in whom they suspected opioid misuse.

Another limitation of our study is its individualized nature. We did not adhere to strict algorithms for diagnosis and treatment and did not test a single intervention. The evidence-base for managing chronic pain in the general medicine setting is limited and the multi-modal nature of our intervention was by necessity empirical and exploratory. As such, we decided to allow more latitude and individualization in treatment choice. We have used our experience and the data collected to develop more robust algorithms to guide the management of pain and depression and to make psychiatric referral when appropriate.

As a corollary to our multi-modal approach, it is difficult to ascertain if the improvements derived from pain medications, intensification of depression therapy, or simply participation in an organized program. Improvements and changes in behavior that occur as a result of becoming a target of special interest in a program are often referred to as a Hawthorne effect $[94,95]$.

\section{Conclusions}

In a 3 month trial conducted in an academic primary care setting, a systematic, multi-disciplinary approach to chronic pain management that included the use of opioids and tools to prevent misuse was effective in improving pain, depression, and function scores. Future efforts will be directed at examining their durability and promoting their sustainability. A randomized control trial would determine whether these are real effects or represent a secular trend.

Comorbid depression and substance misuse were common. Efforts will also be made to further characterize the interaction of these and other comorbid psychiatric conditions with chronic pain. Chronic pain patients with substance abuse are a challenging subset of patients who could benefit from new research and initiatives to mitigate the risk of abuse while ameliorating pain control. 


\section{Competing interests}

The author(s) declare that they have no competing interests.

\section{Authors' contributions}

PC developed the study designand intervention, performed the statistical analyses, and drafted the manuscript.TI developed the study designand intervention, administered surveys and directed pharmacologic management, assisted in editing and revising themanuscript.KF participated in developing the study design, administering surveys, data and projectmanagement, and editing and revising the manuscript. SP participated in study design, developing pharmacologic protocols, performing psychiatric evaluations, and editing and revising the manuscript.TM participated in developing the study design and editing and revising the manuscript.JP assisted in administering surveys, data management and collection, and editing and revising the manuscript.RM participated in the development of the study design, data management, editing and revising the manuscript.MB participated in the development of the study design, editing and revising the manuscript. DD provided statistical analytical support and assisted in the drafting, editing, and revising of the document.MP developed the study design, supervised the overall conduction of the study, participated in data analysis, and assisted in the drafting, editing and revising of the manuscript.

\section{Appendix A: Medication Contract} Patient Name Diagnosis

Physician Name Telephone Number

I agree to abide by the following guidelines for managing my prescription for opiate pain medications:

1. I will only request and receive opiate (narcotic) pain medications from Dr. or from his/her designee in the Internal Medicine Clinic Pain Service. I agree to inform any other physicians participating in my care of this agreement. If another physician wishes to suggest changes in pain management, they can contact Dr. during regular business hours, but no changes will be made without such contact.

2. Dr. and I have agreed that I will receive the following:

medicine directions tity , per days, medicine directions tity _ $\_$per __ days,

medicine directions quantity , per days.

I will not request refills prior to this date. I understand that if my medicines are lost or stolen, they will not be refilled prior to the next refill date. If I use up my supply of medication before the date of the next refill, I understand that my doctor will not provide extra medication. I further understand that I may suffer symptoms of withdrawal. I will inform my doctor in a timely manner if I miss taking a dose of my medication, have an increased need for the pain medication, or have difficulty taking the medication as prescribed. If I find that the current dose of pain medication is no longer adequate, I will discuss this situation with my doctor at a scheduled visit.

\begin{tabular}{lrrr}
3. & agree & to & use \\
\hline Pharmacy, & located & at \\
& for
\end{tabular}

4. I will bring all unused pain medicine to every office visit, including all current prescription vials.

5. While this contract is in effect I will not abuse alcohol or other illicit drugs. As a part of this program, urine drug screening will occur at enrollment and may be required at future visits.

\section{I will not sell or share opiate medications.}

7. If I violate the terms of this contract, I understand that my doctor and other doctors in the Internal Medicine Clinic will no longer prescribe opiate medications for me. If this occurs, I understand that I may receive care elsewhere or continue with my current doctor and not receive opiate medicines. If I change doctors, I agree to allow my current physician to contact my new physician to transfer medical information including information about chronic pain treatment.

8. I understand that my doctor may verify whether or not I have a history of criminal drug convictions.

Patient

Signature

(print

name) 
Physician

Date

\section{Appendix B \\ UNC General Internal Medicine Practice}

\section{Pain Review Committee:}

Policy on Serious Opioid or Controlled Substance Misuse \& Misconduct

\section{Definition}

The Pain Review Committee defines serious misuse or misconduct with regard to opioid medications and other controlled substances as any of the following:

\section{Forgery or alteration of prescriptions.}

2. Use of cocaine or other stimulant medications (e.g. amphetamines) concurrently with prescribed opioids and their detection on urine toxicological testing. Stimulant abuse is strongly indicative of polysubstance abuse.

\section{Diversion of opioids or controlled substances.}

4. Doctor collecting or shopping: Procuring controlled substances from more than one provider and misrepresenting the fact. This is a felony in North Carolina.

5. Negative or "clean" urines: The absence of prescribed opioids from urine toxicological testing on at least two occasions in the context of a history that the patient is taking the medication as directed. This finding suggests diversion and/or substituting a separate urine sample.

6. Inappropriate or inconsistent urines: The presence on urine toxicological testing of opioids or other controlled substances (excluding cannabinoids) not prescribed by our clinic or pain program on at least two occasions without a reasonable explanation. This finding suggests polysubstance abuse, doctor collecting, or drug bartering (a form of diversion).

\section{$\underline{\text { Procedure }}$}

Serious misuse or misconduct is a special category of misuse. It results in the immediate discontinuation of opioids in the Internal Medicine Clinic. The Pain Review Committee will address instances of serious misuse on an expedited basis. Individual cases will not require the review of the entire committee. The following procedure applies:

- The specific violation will be documented in the electronic medical record.

- Instances of serious misuse discovered by the pain management team will be discussed with the patient's primary care provider (PCP).

- The provider who discovers the violation will report it to the Clinic Director, Dr. Thomas Miller, or designee on the Pain Review Committee. (The designee will be either Dr. Paul Chelminski or Dr. Timothy Ives.) The designee will inform Dr. Miller of the violation and make a recommendation to Dr. Thomas Miller and the entire Pain Review Committee for the immediate discontinuation of opioids.

- Dr. Miller will make the final disposition on the recommendation.

- Committee members will receive communication about recommendations and disposition through email. Committee members may recommend alternative sanctions.

- The PCP will be informed of the disposition.

- The patient will receive verbal and written notice of disposition.

\section{$\underline{\text { Sanctions }}$}

A. Serious misuse or misconduct will lead to one of two possible sanctions:

1. Forgery or alteration of prescriptions and diversion will result in immediate and permanent discontinuation of opioids and/or other controlled substances. The clinic director will decide whether instances of forgery or diversion also merit dismissal from the clinic.

2. Stimulant use, doctor collecting/shopping, negative urines, or inappropriate urines will result in immediate discontinuation of opioids and/or other controlled substances with possible re-evaluation in six months for a first violation. The Committee will stipulate substance abuse counseling as a condition for re-evaluation.

B. Two serious violations of the medication contract will result in permanent discontinuation of controlled substances.

\section{Provider Issues}


1. The Pain Review Committee cannot compel attending physicians to cease prescribing opioids or other controlled substances; however, providers who continue to prescribe these medications must understand that this practice may jeopardize their DEA license and/or expose them to regulatory and even criminal investigation. If the attending continues to prescribe opioids after a recommendation of discontinuation by the Committee, the patient is not eligible for re-enrolment in the General Internal Medicine Pain Program after six months.

2. The responsibility for stewardship and teaching of resident physicians requires special oversight of residents' patients who receive controlled substances. The residency program has an obligation to promote appropriate clinical practice and protect residents from practices that may jeopardize their professional status. In addition, residents prescribe scheduled substances under the authority of the hospital's DEA number, and the inappropriate prescription of opioids may expose the hospital to sanction. If the committee recommends discontinuation of opioids for the patient of a resident, the committee will instruct the resident that he or she can no longer prescribe scheduled medications for this patient. Likewise, other residents in the practice are not authorized to prescribe opioids to patients of residents or attendings who have had opioids discontinued.

\section{Communication of Decisions}

1. The patient should be informed of discontinuation verbally. Usually, this responsibility will fall to the PCP, but in certain instances it may fall to the person discovering the violation (e.g. the pharmacist who sees the patient in clinic for follow up in the pain program).

2. Dr. Miller will send the patient a registered letter.

3. The PCP will be copied on the letter.

4. A copy of the letter will be entered into the permanent electronic medical record as a Phone Message.

5. The patient's problem list on the electronic medical record will contain the entry "VIOLATION OF MEDICATION CONTRACT" and will be annotated "PATIENT VIOLATED THE MEDICATION CONTRACT SIGNED WITH GENERAL MEDICINE, AND WAS DISMISSED FROM NARCOTICS - SEE [date] CIS NOTE."

\section{Acknowledgements}

Findings previously presented at Innovations in Practice Management Oral Session at annual meeting of the Society of General Internal Medicine, Chicago, Illinois, 2004. Abstract Title: A Primary Care Disease Management Program for Patients with Chronic Non-Malignant Pain

\section{References}

I. Elliott AM, Smith BH, Penny KI, Smith WC, Chambers WA: The epidemiology of chronic pain in the community. Lancet 1999 , 354(9 I 86): I 248-52.

2. van Tulder M, Koes B, Bombardier C: Low back pain. Best Pract Res Clin Rheumatol 2002, I 6(5):761-75.

3. Mannix LK: Epidemiology and impact of primary headache disorders. Med Clin North Am 200 I, 85(4):887-95.

4. Lipton RB, Stewart WF, Diamond S, Diamond ML, Reed M: Prevalence and burden of migraine in the United States: data from the American Migraine Study II. Headache 200I, 4I(7):646-57.

5. Stewart WF, Ricci JA, Chee E, Morganstein D, Lipton R: Lost Productive Time and Cost Due to Common Pain Conditions in the US Workforce. JAMA 2003, 290( I 8):2443-54.

6. Melzack R: The tragedy of needless pain. Sci Am 1990, 262(2):27-33.

7. Lipton RB, Diamond S, Reed M, Diamond ML, Stewart WF: Migraine diagnosis and treatment: results from the American Migraine Study II. Headache 200I, 4 I (7):638-45.

8. Ghodse $\mathrm{H}$ : Pain, anxiety and insomnia - a global perspective on the relief of suffering: comparative review. $\mathrm{Br} J$ Psychiatry 2003, I83:|15-2|.

9. Olsen Y, Daumit GL: Chronic pain and narcotics: a dilemma for primary care. J Gen Intern Med 2002, I 7(3):238-40.

10. McQuay $\mathrm{H}$ : Opioids in chronic non-malignant pain. $B M J 200 \mathrm{I}$, 322(7295): I I34-5.

II. Jamison RN, Raymond SA, Slawsby EA, Nedeljkovic SS, Katz NP: Opioid therapy for chronic noncancer back pain. A randomized prospective study. Spine 1998, 23(23):259|-600.

12. Moulin DE, lezzi A, Amireh R, Sharpe WK, Boyd D, Merskey H: Randomised trial of oral morphine for chronic non-cancer pain. Lancet 1996, 347(8995): |43-7.

13. Deyo RA, Weinstein JN: Low Back Pain. N Engl J Med 200I, 344(5):363-70.

14. Cleeland CS, Gonin R, Hatfield AK, Edmonson JH, Blum RH, Stewart JA, Panda KJ: Pain and its treatment in outpatients with metastatic cancer. N Engl J Med I 994, 330(9):592-6.

15. Joranson DE, Ryan KM, Gilson AM, Dahl JL: Trends in medical use and abuse of opioid analgesics. JAMA 2000, 283(13): 1710-4.

16. Portenoy RK: Chronic opioid therapy in nonmalignant pain. $J$ Pain Symptom Manage 1990, 5(I Suppl):S46-62.

17. Gardner-Nix J: Principles of opioid use in chronic noncancer pain. CMAJ 2003, I 69(I):38-43.

18. DeAngelis CD: Pain Management. JAMA 2003, 290( I 8):2480-I.

19. Gelfand SG: Opioids and rheumatic disease pain: comment on the article by Ytterberg et al. Arthritis Rheum I999, 42(4):830-I.

20. Jamison RN, Ross E: Show us the evidence: a reply to Bartleson's article. Pain Medicine 3(3):272-3.

21. Bartleson JD: Evidence for and against the use of opioid analgesics for chronic nonmalignant low back pain: a review... including commentary by Jamison RN and Ross E. Pain Medicine 2002, 3(3):260-73.

22. Rowbotham MC, Twilling L, Davies PS, Reisner L, Taylor K, Mohr D: Oral Opioid Therapy for Chronic Peripheral and Central Neuropathic Pain. N Engl J Med 2003, 348(13): I 223-32.

23. Allan L, Hays $H$, Jensen NH, de Waroux BL, Bolt M, Donald R, Kalso $\mathrm{E}$ : Randomised crossover trial of transdermal fentanyl and sustained release oral morphine for treating chronic noncancer pain. BMJ 200I, 322(7295): I I54-8.

24. Ytterberg SR, Mahowald ML, Woods SR: Codeine and oxycodone use in patients with chronic rheumatic disease pain. Arthritis Rheum 1998, 4 I(9): I603-12.

25. Hill PA, Hardy PA: The cost-effectiveness of a multidisciplinary pain management programme in a district general hospital. The Pain Clinic 1996, 9(2): 181-88.

26. McCarberg B, Wolf J: Chronic pain management in a health maintenance organization. Clin J Pain 1999, I 5(I):50-7.

27. Adams NJ, Plane MB, Fleming MF, Mundt MP, Saunders LA, Stauffacher EA: Opioids and the treatment of chronic pain in a primary care sample. J Pain Symptom Manage 200I, 22(3):79I-6.

28. Von Korff M, Simon G: The relationship between pain and depression. Br J Psychiatry Suppl 1996:101-8.

29. Bair MJ, Robinson RL, Katon W, Kroenke K: Depression and Pain Comorbidity: A Literature Review. Arch Intern Med 2003, I 63(20):2433-45. 
30. Romano JM, Turner JA: Chronic pain and depression: does the evidence support a relationship? Psychol Bull I985, 97(I): I8-34.

31. Greenberg PE, Leong SA, Birnbaum HG, Robinson RL: The economic burden of depression with painful symptoms. J Clin Psychiatry 2003, 64(Suppl 7): 17-23.

32. Jamison RN, Gintner L, Rogers JF, Fairchild DG: Disease management for chronic pain: barriers of program implementation with primary care physicians. Pain Medicine 2002, 3(2):92-101.

33. Fujimoto D: Regulatory issues in pain management. Clin Geriatr Med 200I, I 7(3):537-5I. vii

34. Joranson DE: Federal and state regulation of opioids. J Pain Symptom Manage 1990, 5(I Suppl):SI2-23.

35. Bodenheimer T, Wagner EH, Grumbach K: Improving primary care for patients with chronic illness: the chronic care model, Part 2. JAMA 2002, 288(I5):1909-14.

36. Bodenheimer T, Wagner EH, Grumbach K: Improving primary care for patients with chronic illness. JAMA 2002, 288( (14): I775-9.

37. Bodenheimer $\mathrm{T}$ : Disease management - promises and pitfalls. N Engl J Med I 999, 340(I5): | 202-5.

38. Harris JM Jr: Disease management: new wine in new bottles? Ann Intern Med 1996, I 24(9):838-42.

39. Epstein RS, Sherwood LM: From outcomes research to disease management: a guide for the perplexed. Ann Intern Med 1996, 1 24(9):832-7.

40. Donovan MI, Evers K, Jacobs $\mathrm{P}$, Mandleblatt $\mathrm{S}$ : When there is no benchmark: designing a primary care-based chronic pain management program from the scientific basis up. Journal of Pain \& Symptom Management 1999, I 8(I):38-48.

4I. Rothman R, Malone R, Bryant B, Horlen C, Pignone M: Pharmacistled, primary care-based disease management improves hemoglobin A $\mathrm{c}$ in high-risk patients with diabetes. Am J Med Qual 2003, 18(2):5I-8.

42. Cleland CS: Measurement of Pain by Subjective Report. Issues in Pain Measurement. Volume 12. New York: Raven Press; 1989:391-403.

43. Cleland CS: Assessment of Pain in Cancer: Measurement Issues. Proceedings of the Second International Congress on Cancer Pain. Volume 16. New York: Raven Press; 1990:47-56.

44. Pengel LH, Herbert RD, Maher CG, Refshauge KM: Acute low back pain: systematic review of its prognosis. BMJ 2003 , 327(7410):323.

45. Karjalainen $K$, Malmivaara $A$, van Tulder $M$, Roine $R$, Jauhiainen $M$, Hurri $\mathrm{H}$, Koes B: Multidisciplinary biopsychosocial rehabilitation for neck and shoulder pain among working age adults. Cochrane Database Syst Rev 2003:CD002194.

46. Chibnall JT, Tait RC: The Pain Disability Index: factor structure and normative data. Arch Phys Med Rehabil 1994, 75(10): 1082-6.

47. Tait RC, Pollard CA, Margolis RB, Duckro PN, Krause SJ: The Pain Disability Index: psychometric and validity data. Arch Phys Med Rehabil 1987, 68(7):438-4I.

48. Radloff $L$ : $A$ self-report depression scale for research in the general population. Appl Psychol Meas 1977, I:385-92

49. Fishman SM, Kreis PG: The opioid contract. Clin J Pain 2002, I8(4 Suppl):S70-5

50. Tests for drugs of abuse. Med Lett Drugs Ther 2002, 44(I I 37):7I-3.

51. Hammett-Stabler CA, Pesce AJ, Cannon DJ: Urine drug screening in the medical setting. Clin Chim Acta 2002, 3 I 5(I-2): 125-35.

52. Savage SR: Opioid use in the management of chronic pain. Med Clin North Am 1999, 83(3):76I-86.

53. Portenoy RK: Opioid therapy for chronic nonmalignant pain: a review of the critical issues. J Pain Symptom Manage 1996, I I(4):203-I7.

54. Model Guidelines for the Use of Controlled Substances for the Treatment of Pain Federation of State Medical Boards 2003 [http://www.fsmb.org/].

55. Rischitelli DG, Karbowicz SH: Safety and efficacy of controlledrelease oxycodone: a systematic literature review. Pharmacotherapy 2002, 22(7):898-904.

56. Geisser ME, Roth RS, Robinson ME: Assessing depression among persons with chronic pain using the Center for Epidemiological Studies-Depression Scale and the Beck Depression Inventory: a comparative analysis. Clin J Pain 1997, I3(2): 163-70.
57. Flor H, Fydrich T, Turk DC: Efficacy of multidisciplinary pain treatment centers: a meta-analytic review. Pain 1992, 49(2):221-30

58. Farrar JT, Young JP Jr, LaMoreaux L, Werth JL, Poole RM: Clinical importance of changes in chronic pain intensity measured on an II-point numerical pain rating scale. Pain 200I, 94(2): | 49-58.

59. Bair MJ, Robinson RL, Eckert GJ, Stang PE, Croghan TW, Kroenke K: Impact of pain on depression treatment response in primary care. Psychosom Med 2004, 66(I): 17-22.

60. Peters L, Simon EP, Folen RA, Umphress V, Lagana L: The COPE program: treatment efficacy and medical utilization outcome of a chronic pain management program at a major military hospital. Mil Med 2000, I 65( I 2):954-60.

6I. Porter J, Jick $\mathrm{H}$ : Addiction rare in patients treated with narcotics. N Engl J Med I 980, 302(2): 123.

62. Hoffmann NG, Olofsson O, Salen B, Wickstrom L: Prevalence of abuse and dependency in chronic pain patients. Int J Addict 1995, 30(8):919-27.

63. Fishbain DA: Report on the prevalence of drug/alcohol abuse and dependence in chronic pain patients (CPPs). Subst Use Misuse 1996, 31 (8):945-6.

64. Reid MC, Engles-Horton LL, Weber MB, Kerns RD, Rogers EL, O'Connor PG: Use of opioid medications for chronic noncancer pain syndromes in primary care. J Gen Intern Med 2002, I7(3): I73-9.

65. Weissman DE, Haddox JD: Opioid pseudoaddiction - an iatrogenic syndrome. Pain 1989, 36(3):363-6.

66. Maier C, Hildebrandt J, Klinger R, Henrich-Eberl C, Lindena G: Morphine responsiveness, efficacy and tolerability in patients with chronic non-tumor associated pain - results of a doubleblind placebo-controlled trial (MONTAS). Pain 2002, 97(3):223-33

67. Colvin R: Prescription Drug Addiction. Omaha: Addicus Books 2002.

68. Meier B: Pain Killer: A "Wonder" Drug's Trail of Addiction and Death. USA: Rodale 2003.

69. Bloodsworth D: Legal drugs may be tracked. Orlando Sentinel 2003:I-3.

70. Belluck P: Methadone grows as killer drug. The New York Times 2003

7I. Ballesteros MF, Budnitz DS, Sanford CP, Gilchrist J, Agyekum GA Butts J: Increase in deaths due to methadone in North Carolina. JAMA 2003, 290(I):40.

72. Interim report of the President's New Freedom Commission on Mental Health 2004 [Http://www.Mentalhealthcommis sion.Gov/Reports/Interim Report.Htm]

73. OxyContin®: Diversion \& Abuse. U.S. Drug Enforcement Agency, Office of Diversion Control 2003.

74. Soderstrom CA, Dischinger PC, Kerns TJ, Kufera JA, Mitchell KA Scalea TM: Epidemic increases in cocaine and opiate use by trauma center patients: documentation with a large clinical toxicology database. J Trauma 200 I, 5 I (3):557-64.

75. New drug policy puts focus on prescriptions. Use of painkillers, sedatives, stimulants to be monitored. The Associated Press [http://msnbc.msn.com/id/4422582/]. March I, 2004

76. Findings and Recommendations of the Task Force to Prevent Deaths from Unintentional Drug Overdoses in North Carolina. Executive Summary. North Carolina Department of Health and Human Services. Division of Public Health Injury Prevention Branch 2004.

77. Roth SH, Fleischmann RM, Burch FX, Dietz F, Bockow B, Rapoport RJ, Lacouture PG: Around-the-clock, controlled-release oxycodone therapy for osteoarthritis-related pain: placebo-controlled trial and long-term evaluation. Arch Intern Med 2000, 160(6):853-60.

78. Regier DA, Farmer ME, Rae DS, Locke BZ, Keith SJ, Judd LL, Goodwin FK: Comorbidity of mental disorders with alcohol and other drug abuse. Results from the Epidemiologic Catchment Area (ECA) Study. JAMA 1990, 264(19):25। I-8.

79. Portenoy RK, Sciberras A, Eliot L, Loewen G, Butler J, Devane J: Steady-state pharmacokinetic comparison of a new, extended-release, once-daily morphine formulation, Avinza, and a twice-daily controlled-release morphine formulation in patients with chronic moderate-to-severe pain. Journal of Pain \& Symptom Management 2002, 23(4):292-300. 
80. Arkinstall W, Sandler A, Goughnour B, Babul N, Harsanyi Z, Darke $A C$ : Efficacy of controlled-release codeine in chronic nonmalignant pain: a randomized, placebo-controlled clinical trial. Pain 1995, 62(2): 169-78.

81. Iglehart JK: The Mental Health Maze and the Call for Transformation. N Engl J Med 2004, 350(5):507-I4.

82. Kavanagh DJ, McGrath J, Saunders JB, Dore G, Clark D: Substance misuse in patients with schizophrenia: epidemiology and management. Drugs 2002, 62(5):743-55.

83. Rosenblum A, Joseph H, Fong C, Kipnis S, Cleland C, Portenoy RK: Prevalence and Characteristics of Chronic Pain Among Chemically Dependent Patients in Methadone Maintenance and Residential Treatment Facilities. JAMA 2003, 289(18):2370-8.

84. Friedman $\mathrm{R}$, Li $\mathrm{V}$, Mehrotra $\mathrm{D}$ : Treating pain patients at risk: evaluation of a screening tool in opioid-treated pain patients with and without addiction. Pain Med 2003, 4(2): $182-5$.

85. Passik SD, Kirsh KL: The need to identify predictors of aberrant drug-related behavior and addiction in patients being treated with opioids for pain. Pain Med 2003, 4(2): 186-9.

86. Turk DC, Okifuji A: Assessment of patients' reporting of pain: an integrated perspective. Lancet 1999, 353(9/66): 1784-8.

87. Wells KB, Stewart A, Hays RD, et al:: The functioning and wellbeing of depressed patients. Results from the Medical Outcomes Study. JAMA 1989, 262(7):9|4-9.

88. Burton AK, Tillotson KM, Main C], Hollis S: Psychosocial predictors of outcome in acute and subchronic low back trouble. Spine 1995, 20(6):722-8.

89. Dunbar SA, Katz NP: Chronic opioid therapy for nonmalignant pain in patients with a history of substance abuse: report of 20 cases. J Pain Symptom Manage 1996, I I(3): I63-7I.

90. Webb L, Oyefeso A, Schifano F, Cheeta S, Pollard M, Ghodse AH: Cause and manner of death in drug-related fatality: an analysis of drug-related deaths recorded by coroners in England and Wales in 2000. Drug Alcohol Depend 2003, 72(I):67-74.

91. United States Department of Justice, DEADCP: A Closer Look At State Prescription Monitoring Programs [Web Page]. [http:/ /www.deadiversion.usdoj.gov/pubs/program/rx monitor/index.html]. Accessed I December 2004

92. Clark JD: Chronic pain prevalence and analgesic prescribing in a general medical population. J Pain Symptom Manage 2002, 23(2): $|3|-7$.

93. Turk DC: Here we go again: outcomes, outcomes, outcomes. Clin J Pain 1999, 15(4):24I-3.

94. Fletcher RH, Fletcher SW, Wagner EH: Clinical Epidemiology Thirs edition. Philadelphia: Lippincott Williams \& Wilkins; 1996.

95. Veney JE, Kaluzny AD: Evaluation \& Decision Making for Health Services Chicago, Illinois: Health Administration Press; 1998.

\section{Pre-publication history}

The pre-publication history for this paper can be accessed here:

http://www.biomedcentral.com/1472-6963/5/3/prepub

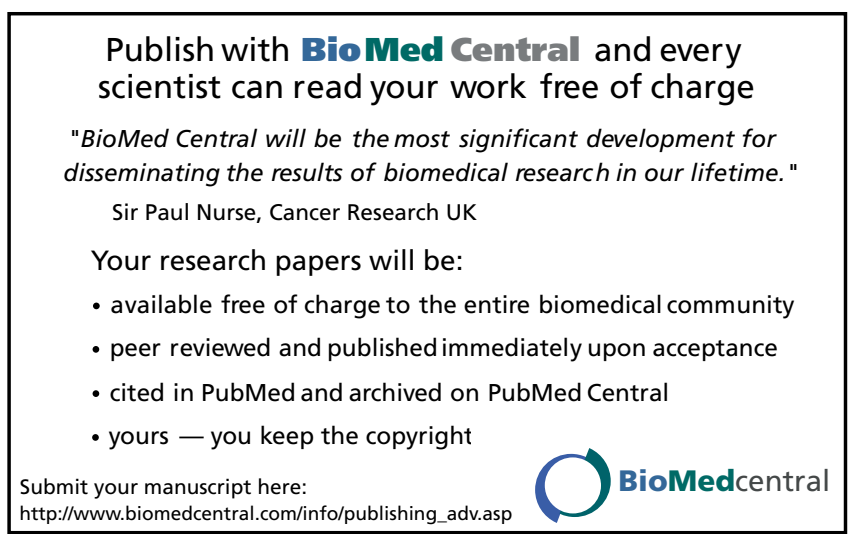

